\title{
Effect of Music Appreciation During Dental Treatment on Dental Fear
}

\author{
Man Hyu Huh ${ }^{1}$, Hye-Jin Kim ${ }^{2}$ \\ ${ }^{1}$ Professor, Department Of Molecular Biology, Dong-Eui University, Republic Of Korea \\ ${ }^{2}$ Assistant Professor, Department Of Dental Hygiene, Dong-Eui University, Republic Of Korea
}

\begin{abstract}
This study was attempted to investigate whether playing music would have an effect on the reduction of dental fear during dental treatment or not. The study was surveyed in the dental clinics located in Busan City, with 100 patients who did not have difficulty in appreciating music and 100 patients who did not listen to music. To a question about what impact music appreciation during examination had on anxiety, most of the respondents feel comfortable. Dental fear was the highest in the respondents who responded, "I am afraid of pain or discomfort" in dental treatment after music appreciation; There was a little difference in dental fear in the patients who appreciated music during dental treatment from those who did not.
\end{abstract}

Keywords: Dental clinics, Dental fear, Playing music

\section{Introduction}

Most people were aware that they could ask for help to arrange and make dental visits. With Westernized dietary habit and life, the number of people who go to the dentist has naturally increased. In addition, these days, an aesthetic interest in teeth tends to increase as well as the purpose of treatment. As knowledge and awareness about dental health increase through oral health education in school or kindergarten, the number of dental clinics increases and a variety of information is shared widely and spread rapidly through the internet and smart phones, so there is an increasing interest in more efficient dental treatment and medical techniques gradually increase. However, in spite of the development of dental treatment techniques, anxiety about dental treatment and fear of pain experienced during treatment are still problems. There are people who postpone the necessary treatment because of anxiety and fear about dental treatment or even those who do not have the necessary treatment ${ }^{1}$. Therefore, oral health business planners or operators are concerned about anxiety and fear for dental treatment, as well. It is very difficult to deal with patients anxious about dental treatment, which results in a longer treatment time during dental treatment and giving a mental burden to the operator ${ }^{1}$. Fear has negative impacts on the dentist's treatment attitude and behavior.

Emotion of anxiety is an unconscious state, which is concern, stress and worry occurring while a vague and uncertain situation is expected while fear is consciously recognized and a response to a normal external threat or risk ${ }^{2}$. There are people who have vague anxiety about dental clinic, but there are people who come to have anxiety about the pain or feeling from the experience of dental treatment in the past. Anxiety and fear about the pain felt during dental treatment make many patients postpone or avoid receiving dental treatment ${ }^{3}$, and as a result, it was reported that many left a disease till it aggravated and turned into an emergency situation ${ }^{4}$. They feel the vague anxiety about dental clinic greater than the pain due to the aggravation of the disease. In a report on epidemiological research in Busan related to dentists and dental treatment, adults, $5-15 \%$ of the population did not receive dental treatment because of anxiety, and the rate is similar in all countries ${ }^{5,6}$. According to Friedson \& Feldman, it was reported that $9 \%$ of the total population had not received treatment due to fear of dental treatment.

According to research conducted regarding the actual contents of treatment, $88 \%$ of the patients reported that they felt anxiety and fear before the treatment; $57 \%$ had anxiety and fear because of the noise of the dental machinery; $32 \%$ had anxiety because of the injection for the gum anesthesia; $16 \%$ had fear about the extraction of tooth; $11 \%$ had anxiety and fear about the overall dental treatment ${ }^{7}$. For the alleviation of this fear or anxiety during dental treatment, various methods have been used, and as a method for obtaining such an effect, music appreciation by earphones, video vision, experience glasses of virtual reality, TV monitor (Virtual vision) and recently, various useful devices such as an air-pressure painless therapeutic device and a laser drill instead of a drill (hand piece) have been developed and used. These devices decrease patients' fear when used according to their functions and sometimes, they completely remove the pain. In fact, it is reported that these methods had great effects on dental anxiety and fear ${ }^{8}$.

Of these methods, music therapy is one of the methods most widely used. The use of music including music appreciation is a cognitive strategy and a type of the methods of shifting attention, which weakens the perception of anxiety and pain accompanying the treatment process by the refocusing on a more positive stimulation in the negative aspect of treatment ${ }^{9,10}$. For this reason, it can allow the patients to get treatment, 
listening to their favorite music at suitable volume and shift their attention to a different thing, so it has been reported that it was effective for pain relief during dental treatment, and that the music used in the treatment had a calming effect ${ }^{11,12}$.

\subsection{Collecting Methods}

\section{Methods}

This study was selected some dental clinics located at Busan-ci in Korea. Samplings were collected monthly from November 2014 to March 2015. We explained the research purpose to the patients who visited the institutions, obtained their agreement and conducted a survey after the completion of treatment. The patients did not have any difficulty in music appreciation. They agreed to participate in this project and were divided into an experimental group: the treatment (100 persons) and a control group (100 persons).

\subsection{Research Methods}

Questionnaires about the participating patients' general characteristics, dental anxiety/fear scale and state anxiety were drawn up with a self-administered method. The composition of the questionnaires was modified and supplemented, based on the preceding studies ${ }^{1}$ for the purpose of this study. Spielberger's dental anxiety/fear scale consists of four-point Likert scale, ranging between 20 and 80, and the higher the score, the higher the level of anxiety becomes.

\subsection{Analysis of Date}

The collected data were analyzed, using SPSS for Windows Ver. 18.0, and the detailed method of analysis is as follows. This study conducted $\mathrm{x}^{2}$ tests of age distribution according to the sex of the research subjects, experience of dental fear according to the classification of dental treatment and the level of experience of pain, a frequency analysis of the level of the impact of music appreciation on dental treatment, a t-test of the level of dental fear according to music appreciation and an ANOVA of the level of dental fear during dental treatment after music appreciation.

\section{Results}

There were 35 women aged under 24; 24 women aged between 25 and 34; and 25 women over 35 white there were 72 men aged under 24; 20 men aged between 25 and 34; and 25 men aged over 35 (Table 1).

Table 1: Gender and age

\begin{tabular}{|c|c|c|c|}
\hline \multirow{2}{*}{ Gender } & \multicolumn{3}{|c|}{ Age } \\
\cline { 2 - 4 } & Under 24 & $25-34$ & Over 35 \\
\hline Female & $35(17.5)$ & $24(12.0)$ & $25(12.5)$ \\
\hline Male & $72(35.5)$ & $20(10.0)$ & $25(12.5)$ \\
\hline Sum Total & $106(53.0)$ & $44(22.0)$ & $50(25.0)$ \\
\hline
\end{tabular}

As for the experience of fear for treatment according to dental treatment, the group of patients with experience of fear for treatment had the highest fear for cavity treatment during their experience of dental treatment $(27 \%)$, followed by prosthesis treatment (16\%), surgical treatment (13\%), other (8\%) and remedial treatment $(5.5 \%)$, and there were significant differences. In the group of patients without experience of fear for treatment, most responded that they had no experience of fear for treatment (23\%), followed by cavity treatment $(4 \%)$, other $(1.5 \%)$, prosthesis treatment $(1 \%)$, surgical treatment $(0.5 \%)$ and remedial treatment $(0.5 \%)$, and there were significant differences (Table 2).

Table 2: Classification of dental treatment according to fear for treatment experience

\begin{tabular}{|c|c|c|c|c|c|c|c|}
\hline $\begin{array}{l}\text { Experience of } \\
\text { fear for } \\
\text { treatment }\end{array}$ & $\begin{array}{l}\text { No treatment } \\
\text { experience }\end{array}$ & $\begin{array}{l}\text { Cavity } \\
\text { treatment }\end{array}$ & $\begin{array}{l}\text { Prosthesi } \\
\quad \mathrm{s} \\
\text { treatment }\end{array}$ & $\begin{array}{l}\text { Surgical } \\
\text { treatment }\end{array}$ & $\begin{array}{l}\text { Remedi } \\
\text { al } \\
\text { treatme } \\
\text { nt }\end{array}$ & Other & $x^{2}$ \\
\hline Yes & - & $54(27.0)$ & $32(16.0)$ & $26(13.0)$ & $11(5.5)$ & $16(8.0)$ & \multirow{2}{*}{$\begin{array}{c}24.128 \\
(.001) \\
\end{array}$} \\
\hline No & $46(23.0)$ & $8(4.0)$ & $2(1.0)$ & $1(0.5)$ & $1(0.5)$ & $3(1.5)$ & \\
\hline Total (\%) & $46(23.0)$ & $62(31.0)$ & $34(17.0)$ & $27(13.5)$ & $12(6.0)$ & $19(9.5)$ & \\
\hline
\end{tabular}

As for the level of experience of pain according to dental treatment, cavity treatment was $16.0 \%$ and prosthesis treatment was $9.0 \%$ in the patients who responded that they did not experience treatment while surgical treatment was $11.0 \%$ and cavity treatment was $10.5 \%$ in those who responded that they experienced 
severe pain, and there were a little more experience of pain in cavity treatment, surgical treatment and prosthesis treatment in those that responded, "I experienced slight or severe pain" than in those who responded, "I experienced pain." (Table 3).

Table 3: Level of experience of pain according to dental treatment

\begin{tabular}{|l|c|c|c|c|c|c|c|}
\hline \multicolumn{1}{|c|}{ Classification } & $\begin{array}{c}\text { No treatment } \\
\text { experience }\end{array}$ & $\begin{array}{c}\text { Cavity } \\
\text { treatment }\end{array}$ & $\begin{array}{c}\text { Prosthesis } \\
\text { treatment }\end{array}$ & $\begin{array}{c}\text { Surgical } \\
\text { treatment }\end{array}$ & $\begin{array}{c}\text { Orthodontic } \\
\text { treatment }\end{array}$ & Other & $x^{2}$ \\
\hline $\begin{array}{l}\text { Experienced } \\
\text { slight pain }\end{array}$ & $23(11.5)$ & $32(16.0)$ & $18(9.0)$ & $4(2.0)$ & $6(3.0)$ & $8(4.0)$ & 10.24 \\
\hline $\begin{array}{l}\text { Experienced } \\
\text { severe pain }\end{array}$ & $11(5.5)$ & $21(10.5)$ & $12(6.0)$ & $22(11.0)$ & $5(2.5)$ & $3(1.5)$ & $(.001)$ \\
\hline Experienced pain & $12(6.0)$ & $9(4.5)$ & $4(2.0)$ & $1(0.5)$ & $1(0.5)$ & $8(4.0)$ & $19(9.5$ \\
\hline \multicolumn{2}{|c|}{ Total $(\%)$} & $46(23.0)$ & $62(31.0)$ & $34(17.0)$ & $27(13.5)$ & $12(6.0)$ & \begin{tabular}{c} 
) \\
\hline
\end{tabular} \\
\hline
\end{tabular}

$* * *: p<0.001$.

Impacts of music appreciation included, 'It makes me comfortable" (37.5\%), followed by "I don't know" (35.0\%), "It alleviates pain" (18.0\%), "It does not matter" (6.0\%) and "It is rather unpleasant" (3.5\%) (Table 4).

Table 4: Level of the impacts of music appreciation on dental treatment

\begin{tabular}{|c|c|}
\hline Impacts of music appreciation & Number (\%) \\
\hline It alleviates pain & $36(18.0)$ \\
\hline It makes me comfortable & $75(37.5)$ \\
\hline I don't know & $70(35.0)$ \\
\hline It is rather unpleasant & $7(3.5)$ \\
\hline It does not matter & $12(6.0)$ \\
\hline Sum Total & $200(100.0)$ \\
\hline
\end{tabular}

Dental fear was the highest in the group of the patients with fear, who responded, "I am afraid of the possibility of pain or discomfort during dental treatment after music appreciation" $(54.11 \pm 6.90)$ while it was the lowest in the group of the patients with a positive emotion, who responded, "I am a little pleasant" $(36.50 \pm 7.71)$. During dental treatment after music appreciation, the more positive their emotion, the lower their dental fear became $(\mathrm{F}=11.081, p<0.001)($ Table 5).

Table 5: Level of dental fear during dental treatment after music appreciation

\begin{tabular}{|c|c|c|}
\hline Classification & Mean \pm SD & $\mathrm{F}(p)$ \\
\hline A little pleasant & $36.50 \pm 7.71$ & \multirow{5}{*}{$\begin{array}{l}11.081 \\
(0.001)\end{array}$} \\
\hline Not that worried & $41.73 \pm 8.12$ & \\
\hline A little worried & $46.80 \pm 8.75$ & \\
\hline Afraid because it may be painful or uncomfortable & $54.11 \pm 6.90$ & \\
\hline Afraid thinking of receiving treatment & $48.57 \pm 9.67$ & \\
\hline Sum Total & $45.54 \pm 9.27$ & \\
\hline
\end{tabular}

At the level of dental fear according to music appreciation, dental fear was significantly higher in the group that did not appreciate music $(45.97 \pm 10.88)$ than in the group that appreciated the music $(45.31 \pm 7.38)$ (Table 6).

Table 6: Level of dental fear according to music appreciation

\begin{tabular}{|l|c|c|c|}
\hline \multicolumn{1}{|c|}{ Music appreciation } & Mean \pm SD & N & $t(p)$ \\
\hline No & $45.97 \pm 10.88$ & 100 & 2.350 \\
\cline { 1 - 2 } Yes & $45.31 \pm 7.38$ & 100 & $(0.05)$ \\
\hline$* p<0.05$.
\end{tabular}

\section{Discussion}

Anxiety about dental treatment and fear for the pain experienced during treatment is still problems in spite of the development of the dental treatment techniques. It is the psychology of the general patients that dental treatment is very uncomfortable as compared to the general treatment or examination ${ }^{13}$. There are people 
who postpone the necessary treatment or people who do not even receive the treatment because of anxiety and fear for dental treatment ${ }^{1}$. If patients have severe anxiety during treatment, their bodies are nervous, which causes more anxiety, decreases treatment compliance and extends treatment time, and the operator, too, feels fatigue. The reduction of the patients' anxiety is important for treatment quality and the subjects' satisfaction, so it is necessary to find an effective method to reduce the patients' dental fear, and this study was conducted to investigate and reveal that music appreciation would be an intervention method effective for the reduction of anxiety.

In this study, women were $58 \%$ while men were $42 \%$, and of all age groups, most patients were under $24(53 \%)$. The score for dental fear in a music appreciation group was 45.31 points while that in the group that did not appreciate music was 45.97 points. There was a slightly higher score for dental fear in the music appreciation group than in the group that did not appreciate music, but there was no big difference.

In a study with middle school students with high anxiety and fear for dental treatment ${ }^{1}$, it was reported that one-time music appreciation did not reduce anxiety about dental treatment; however, in two-time music appreciation, the level of anxiety decreased. In Gfeller ${ }^{14}$, too, as a result of a survey of the level of anxiety with dental patients, it was reported that there was no difference in the score for state anxiety between a control group and an experimental group. Previous studies interpreted that it would be difficult for one-time music appreciation to control anxiety in dental treatment, but continuous music appreciation could result in a different effect. If a music appreciation method can be used after proper adjustment according to various fields of dental treatment, it will be a good method that can intervene in anxiety.

$69.5 \%$ had experience of dental treatment, and $38.8 \%$ had cavity treatment, followed by prosthesis treatment $(23.0 \%)$, surgical treatment $(18.7 \%)$ and remedial treatment $(7.9 \%)$. Of the subjects of this study, people with experiences of prosthesis treatment and surgical treatment had a higher score for anxiety. $42 \%$ of the people who experienced surgical treatment in the past had a score for anxiety in a high range while $25 \%$ of those who experienced prosthetic treatment had a high score for anxiety. Of the subjects with the experience of dental treatment, those who experienced pain were $82 \%$ and $26 \%$ of them had anxiety factors. This was higher than only $11 \%$ of those who did not experience pain had anxiety factors. $46.5 \%$ of patients in the experimental group that appreciated music during dental treatment responded that they were satisfied, and it was reported that pain and anxiety decreased in those who responded that music appreciation alleviated pain (18.0\%) and those who responded that it comforted them (37.5\%). This was consistent with the study on the effects of music appreciation on dental patients' anxiety and pain ${ }^{15}$. In this study, the dental fear was the highest in the group of the patients with an emotion of fear for dental treatment after music appreciation would be painful or uncomfortable while it was the lowest in the group of the patients with a positive emotion, who felt a little pleasant. Also, the more positive the emotion in dental treatment after music appreciation, the lower the dental fear became. Like this, attention shift through music appreciation allows stress control and emotional adjustment and makes patients themselves have positive emotions in the treatment of patients with anxiety about dental treatment, which would be effective for the alleviation of dental fear. In addition, it is judged that music appreciation will be applied as an effective method for reducing mental stability and anxiety in the subjects of dental treatment.

\section{Conclusion}

This study was attempted to investigate whether playing music during dental treatment would have an effect on the reduction of dental fear, and helped by experts in the dental clinics located in B. City, with 100 patients who did not have difficulty in appreciating music and 100 patients who did not listen to music. This study described the research purpose to the patients who visited the clinics and obtained their agreement from November 2014 to March 2015.

1. To a question about what impact music appreciation during examination had on anxiety, most of the respondents responded, "it makes me feel comfortable";

2. Dental fear was the highest in the respondents who responded, "I am afraid of pain or discomfort" in dental treatment after music appreciation; and

3. There was a little difference in dental fear in the patients who appreciated music during dental treatment from those who did not.

In conclusion, there was a little difference in the level of dental fear in the group of persons who appreciated music during dental treatment as compared to that of those who did not, and judging from the high rate of the respondents who responded that music appreciation during dental treatment made them 'feel comfortable,' playing music during dental treatment would have a positive impact on the reduction of anxiety.

\section{References}

[1]. H. Lautch, Dental Phobia, The British Journal of Psychiatry, 1971, 119: 151-158.

[2]. P. Milgrom, L. Fiset, S. Melnick, and P. Weinstein, The prevalence and practice management consequences of dental fear in a major US city, The Journal of the American Dental Association, 1988, 116(6): 641-647. 
[3]. P.A. Doerr, W.P. Lang, L.V. Nyquist, and D.L. Ronis, Factors associated with dental anxiety, The Journal of the American Dental Association, 1998, 129(8): 1111-1119.

[4]. S.H. Han, Causes and treatment of fear of the dentist, The Journal of Dental Clinic, 1991, 11(4): 98-103.

[5]. Y. Satoch, E. Naagai, and M. Sakamura, Relaxation effect of an audiovisual system on dental patients, Part 2 Pulse-Amplitude, The Journal of Nihon University School of Dentistry, 1995, 37(3): 138-145.

[6]. M.E.A. Stouthard, and J. Hoogstraten, Prevalence of dental anxiety in the Netherlands, Community Dentistry and Oral Epidemiology, 1990, 18: 139-142.

[7]. T. Oyama, Y. Sato, T. Kudo, R. Spintage, and R. Droh, Effect of anxiolytic music on endocrine function in surgical patients, in: R. Spintge, and R. Droh (Eds.), Musik in der medizin - music in medicine (Berlin-Heidelberg- New York: Springer, 1987) 169-174.

[8]. L.D. Morris, Q.A. Louw, and K. Grimmer-Somers, The effectiveness of virtual reality on reducing pain and anxiety in burn injury p atients: a systematic review, The Clinic Journal of Pain, 2009, 25: 815-826.

[9]. A.K. Jacox, Pain : A source book for purses and other health professionals (Boston: Little: Brown and Company,1977).

[10]. R. Locsin, The effect of music on the pain of selected post-operative patients, Journal of Advanced Nursing, 1981, 6: 19-25.

[11]. W.J. Gardner, J.C. Licklider, and A.Z. Weisz, Suppression of pain by sound, Science, 1960, 132: 32-33.

[12]. J.L. Rosenberg, A re-evaluation of audioanalgsia, Oral Surgery, Oral Medicine, Oral Pathology, 1964, 17: 3119-324.

[13]. W.S. Son, W.K. Park, and U.K. Kim, Evaluation on the psychosocial status of the orthognathic surgery patient before surgery, The Korean Journal of Orthodontics, 1998, 28: 231-236.

[14]. K. Gfeller, H. Logan, and J. Walker, The effect of auditory distraction and suggestion on tolerance for dental restorations in adolescents and young adults, Journal of Music Therapy, 1990, 27: 13-23.

[15]. H.Y. Kang, The effect of music therapy on the state anxiety, pain in dental patients, The Journal of Korean Academic Society of Nursing Education, 1998, 4: 147-158. 